\title{
COVID-19 vaccine for children: The challenge of making a decision
}

In order to relieve and resolve the COVID-19 pandemic, there are now more than 180 candidate vaccines under development and study. ${ }^{1}$ Some are also now being studied for their use in children and adolescents. ${ }^{2}$ This situation gives rise to a number of reflections about the need and relevance of vaccination in this age group, the ethical aspects involved in these studies, family acceptance of this possibility, and our preparation as pediatricians to participate in and accompany the development of evidence and exercise a critical judgment of outcomes.

Although in the first months of the pandemic investigators focused on the elderly population and on adults with certain risk factors (obesity, hypertension, etc.), children and adolescents have progressively emerged as a group of interest for vaccination. Even though children, in general, may be less capable of keeping their distance from other people or less prone to implementing other protection strategies than adults, the evidence available to date does not suggest that they are at risk for severe SARS-CoV-2 disease. ${ }^{3,4}$ This means that their position as a vaccine target population is based on their role in community transmission and, therefore, community protection. ${ }^{5}$ In addition, given the relative ease with which this infection can spread, it is estimated that at least $80 \%$ of the population should be vaccinated to achieve herd immunity. ${ }^{6}$ In other words, it may be said that, in this age group, there is a need for vaccination that is rather related to a common interest than a particular benefit.

Some reasons for such need are related to the role played by children in infection dissemination. An early insight in this regard is that not all infected children develop symptoms, and those who do, are not always diagnosed in a timely manner. ${ }^{7}$ Data show that children, even asymptomatic ones, have prolonged viral shedding (up to 18 days). However, it has not been possible to establish the infective and contagious nature this may entail. ${ }^{8}$

As an additional analysis, current vaccine studies (in adults) do not include a measurement of viral load and viral shedding as a secondary end-point, nor of viral transmission as exploratory data. ${ }^{6}$ Such lack of information about transmission after vaccination is a missed opportunity when considering the use of the vaccine in the pediatric population.

Some investigators have gone even further and proposed potentially making vaccination mandatory. ${ }^{9}$ They have analyzed the situation based on previously established criteria related to the vaccine, the disease or its implementation. ${ }^{10}$ As a priority criterion, they proposed vaccine safety, not only because of what it implies per se, but also because of the effect it may have on the community's general trust in vaccines. Subsequently, they made considerations about the existence of a population subgroup that is highly affected by COVID-19, the fact that children play a (yet unclear) role in transmission, and vaccine effectiveness. ${ }^{9}$ It is clear that there is a prior step before making a suggestion: research.

Research has difficulties that are inherent to participants' age, directly related to their ability to provide consent. But it also poses ethical aspects because, in order to respect the basic principles, studies should only include participants for whom the trial implies a minimum risk or for whom it offers a potential benefit that outweighs the risks. That is to say, solid evidence about safety should be available, but waiting for the definite outcomes of studies in adults takes time. This is also a dilemma, because waiting for the clear establishment of vaccine safety and effectiveness in adults may significantly delay an effective response to the pandemic. ${ }^{1}$

A potential alternative is starting research with those who are physiologically more similar to adults: healthy adolescents. This would offer an additional advantage: adolescents have a greater understanding of what it means to take part in a clinical trial, although it definitely does not resolve the most challenging aspect that is the inclusion of younger participants and those with a health condition that exposes them to a higher risk for severe disease.

Once the research stage is completed, for vaccines to reach their target population, it is necessary to have family acceptance. Some studies explored this topic. For example, in the United States, $65 \%$ out of 1500 families indicated that they would vaccinate their children. ${ }^{11}$ Another study showed that, in England, $48 \%$ of families are sure they want to vaccinate their children. The concerns about vaccine safety and effectiveness referred to how "quickly" they were developed. ${ }^{12}$ 
Sociocultural aspects may also be relevant in this matter, so these data may hardly be extrapolated to other communities.

Such path, from basic research companies and clinical trial implementation to public health policies, may appear somewhat distant from pediatricians' routine practice. However, the target of such initiatives are our patients and their families. Thus, pediatricians have a direct or indirect participation in the care of children and adolescents affected by COVID-19, in any research required to understand it, and in community education about what research is and its purpose. We can be part of a clinical trial team but we can also be consulted by a family whose child has been invited to participate in a study. We will need to make a critical assessment of study outcomes to define our indications. Such situation poses challenges. It is an invitation to ask ourselves how prepared we are to decide what we believe is necessary, relevant, useful, and ethical for our patients.

\section{María Elina Serra, M.D..$^{a, b}$}

a. Fundación para la Salud Materno Infantil (FUNDASAMIN), Autonomous City of Buenos Aires, Argentina.

b. Assistant Editor, Archivos Argentinaos de Pediatría.

E-mail address:

María Elina Serra, M.D.: meserra@fundasamin.org.ar

http: / / dx.doi.org/ 10.5546/ aap.2021.eng.294

To cite: Serra ME. COVID-19 vaccine for children: The challenge of making a decision. Arch Argent Pediatr 2021;119(5):294-295.

\section{REFERENCES}

1. Mintz K, Jardas E, Shah S, Grady C, et al. Enrolling Minors in COVID-19 Vaccine Trials. Pediatrics. 2021; 147(3):e2020040717.

2. Clinical Trials.gov [Accessed on: May $6^{\text {th }}, 2021$ ]. Available at:https: / / clinicaltrials.gov/ct2 / results?term=vaccine\&c ond $=$ Covid19\&age_v $=\&$ age $=0 \&$ gnd $r=\&$ type $=\& r s l t=\&$ Sea rch=Apply

3. Rabinowicz S, Leshem E, Pessach IM. COVID-19 in the Pediatric Population-Review and Current Evidence. Curr Infect Dis Rep. 2020; 22(11):29.

4. Zimmermann $\mathrm{P}$, Curtis N. Coronavirus Infections in Children Including COVID-19: An Overview of the Epidemiology, Clinical Features, Diagnosis, Treatment and Prevention Options in Children. Pediatr Infect Dis J. 2020; 39(5):355-68.

5. Kao CM, Orenstein WA, Anderson EJ. The Importance of Advancing Severe Acute Respiratory Syndrome Coronavirus 2 Vaccines in Children. Clin Infect Dis. 2021; 72(3):515-8.

6. Eberhardt CS, Siegrist C-A. Is there a role for childhood vaccination against COVID-19? Pediatr Allergy Immunol. 2021; 32(1):9-16.

7. DeBiasi RL, Delaney M. Symptomatic and Asymptomatic Viral Shedding in Pediatric Patients Infected With Severe Acute Respiratory Syndrome Coronavirus 2(SARS-CoV-2): Under the Surface. JAMA Pediatr. 2021; 175(1):16-8.

8. Han MS, Choi EH, Chang SH, Jin B-L, et al. Clinical Characteristics and Viral RNA Detection in Children With Coronavirus Disease 2019 in the Republic of Korea. JAMA Pediatr. 2021; 175(1):73-80.

9. Opel DJ, Diekema DS, Ross LF. Should We Mandate a COVID-19 Vaccine for Children? JAMA Pediatr. 2021; 175(2):125-6.

10. Opel DJ, Diekema DS, Marcuse EK. A critique of criteria for evaluating vaccines for inclusion in mandatory school immunization programs. Pediatrics. 2008; 122(2):e504-10.

11. Goldman RD, Yan TD, Seiler M, Parra Cotanda C, et al. Caregiver willingness to vaccinate their children against COVID-19: Cross sectional survey. Vaccine. 2020; 38(48):7668-73.

12. Bell S, Clarke R, Mounier-Jack S, Walker JL, Paterson P. Parents' and guardians' views on the acceptability of a future COVID-19 vaccine: A multi-methods study in England. Vaccine. 2020; 38(49):7789-98. 